NOTICE: This is the author's version of a work that was accepted for publication in Preventive Medicine. Changes resulting from the publishing process, such as peer review, editing, corrections, structural formatting and other quality control mechanisms may not be reflected in this document. Changes may have been made to this work since it was submitted for publication. A definitive version was subsequently published in Preventive Medicine, Volume 59, February 2014, Pages 1218. http://doi.org/10.1016/j.ypmed.2013.10.022 


\section{Results of a Randomized Controlled Trial to promote Physical Activity Behaviours in Mothers with Young Children}

Sarojini Maria Dos Remedios $\underline{\text { Monteiro }}^{1}$ Western Australian Centre for Health Promotion Research, School of Public Health, PO BOX U1987, Perth, Western Australia, Australia, 6845. Email: ginny.monteiro@gmail.com

\section{Corresponding author}

Jonine Maree Jancey ${ }^{1,2}$ Western Australian Centre for Health Promotion Research, School of Public Health, Curtin UniversityPO BOX U1987, Perth, Western Australia, Australia, 6845. Ph: 610892663807 Email: j.jancey@curtin.edu.au

Satvinder S. Dhaliwal ${ }^{1,2}$ Western Australian Centre for Health Promotion Research, School of Public Health, Curtin University, PO BOX U1987, Perth, Western Australia, Australia, 6845. Email: s.dhaliwal@curtin.edu.au

Peter A. Howat ${ }^{1,2}$ School of Public Health, Curtin University, PO BOX U1987, Perth, Western Australia, Australia,6845. Email: p.howat@curtin.edu.au

Sharyn Burns ${ }^{1}$ Western Australian Centre for Health Promotion Research, School of Public Health, Curtin University, PO BOX U1987, Perth, Western Australia, Australia, 6845. Email: s.burns@curtin.edu.au

Andrew P. Hills ${ }^{3,4}$ Level 3 Aubigny Place, Raymond Terrace, South Brisbane, Queensland, Australia, 4101. Email: ahills@mmri.mater.org.au

Annie S. Anderson ${ }^{4,5}$ Level 7, Mailbox 7

Dundee, Scotland, DD1 9SY.
Un ivers ity ofD undee,

Em ail:a.s.anderson@dundee.ac.uk

${ }^{1}$ Western Australian Centre for Health Promotion Research, School of Public Health, Curtin University, Western Australia, Australia.

${ }^{2}$ Centre for Behavioural Research in Cancer Control, Curtin University, Western Australia, Australia.

${ }^{3}$ Mater Mothers Hospital and Mater Medical Research Institute, Queensland, Australia.

${ }^{4}$ Centre for Musculoskeletal Research, Griffith Health Institute, Griffith University, Queensland, Australia. 
${ }^{5}$ Centre for Public Health Nutrition Research and Centre for Research into Cancer Prevention and Screening, University of Dundee, Dundee, Scotland.

${ }^{7}$ Population Health Sciences, Medical Research Institute, Ninewells Hospital and Medical School, University of Dundee, Dundee, Scotland.

Abstract Word Count: 203

Manuscript Word Count: 3500

\section{Introduction}

Physical inactivity is identified as a modifiable risk factor that is linked to chronic disease in all ages across the globe (World Health Organisation, 2010, World Health Organisation, 2008). It is estimated to cause $6-10 \%$ of the major non-communicable diseases of coronary heart disease, type 2 Diabetes and breast and colon cancer (Lee et al., 2012).

Worldwide, women have lower rates of physical activity compared to men; Australia $51.4 \%$ women vs. $65.8 \%$ men; Canada $54.8 \%$ vs. $64.4 \%$; USA $57.6 \%$ vs. $67.2 \%$; New Zealand 52.2\% vs. 74\% (Bauman et al., 2009). Furthermore, physical activity declines during pregnancy and post-partum period (Liu et al., 2011, Evenson, 2011, Borodulin et al., 2009) and is linked to the demands of multiple role expectations (Ransdell et al., 2004) (e.g. caring for children) and changes in life events leading to lack of time, fatigue, lack of motivation and financial constraints (Bell and Lee, 2005, Borodulin et al., 2008, Symons Downs and Hausenblas, 2004, Brown et al., 2001). Lack of physical activity among pregnant and post-partum women is associated with negative impact on the health of the mother and the child, including gestational diabetes, mental health, musculoskeletal issues and weight gain (Tobias et al., 2011, Pivarnik et al., 2006).

In 2007-08, 45\% of Australian women of childbearing age (25 and 34 years) were overweight or obese and $75 \%$ were classified as sedentary or had a low activity level (Australian Bureau of Statistics, 2009). Women's propensity to become overweight and obese during the childbearing years is linked to high body mass index (BMI) prior to pregnancy, excessive gestational weight gain, failure to lose excessive weight in the postpartum period within a 12 month timeframe and inter-pregnancy weight gain (Keitt et al., 2008, Ryan, 2007, Davis et al., 2010, Callaway et al., 2006). Obese women of childbearing age are at greater risk of short-term adverse health consequences during pregnancy and postpartum period (Ramachenderan et al., 
2008, Ruager-Martin et al., 2010) and long-term weight retention (Linne et al., 2004, Rooney et al., 2005). Evidence also demonstrates that individuals who are overweight or obese and inactive face the highest risk of morbidity or mortality (Lee et al., 2009, Siega-Riz et al., 2009, Gore et al., 2003). Hence, improving the physical activity levels of mothers with young children is important from a public health perspective.

Systematic literature reviews report on a number of interventions for pregnant women and mothers with children (Amorim et al., 2007, Birdsall et al., 2009, Dodd et al., 2010, Hartman et al., 2010, Keller et al., 2008, Kuhlmann et al., 2008, Lombard et al., 2009b, Ronnberg, 2010, Skouteris et al., 2010). However, a review of the literature demonstrates that there are limited community based randomized controlled trials addressing diet and physical activity specifically designed for mothers with young children (O'Toole et al., 2003, Craigie et al., 2011, Fahrenwald and Sharma, 2002, Fjeldsoe et al., 2010, Liu et al., 2009, Lombard et al., 2009a, Miller et al., 2002). Further, some of these interventions only include women with Body Mass Index <25 (O'Toole et al., 2003) or those who are ready to be more physically active (Fjeldsoe et al., 2010). Hence, there is a urgent need for further research on tailored dietary and physical activity interventions for mothers with young children (Amorim et al., 2007, Birdsall et al., 2009, Dodd et al., 2010, Hartman et al., 2010, Keller et al., 2008, Kuhlmann et al., 2008, Ronnberg, 2010, Skouteris et al., 2010, Streuling et al., 2010, Thangaratinam and Jolly, 2010).

Becoming a mother is a redefining time for health, as health behaviours are often altered to accommodate the needs of motherhood (Walker and Wilging, 2000). It has been reported that after having babies women are motivated to participate in programs to reduce their weight (Bastion et al., 2011) It therefore may be an opportunistic time to commence health promotion activities to improve women's immediate and long-term health (Walker and Wilging, 2000), which in turn will impact on the health of the children.

Recent evidence also reports that as little as one hour of moderate intensity physical activity per week can significantly reduce women's risk of cardiovascular diseases, diabetes, breast cancer and endometrial cancer (U.S. Department of Health and Human Services (USDHHS), 1996, Brown et al., 2007). Accordingly, this study aimed to increase the levels of physical activity of mothers via a home-based intervention conducted in playgroups (Reminder on Food, Relaxation, Exercise and 
Support for Health: REFRESH). This paper presents changes in physical activity and muscle strength exercise from baseline to post-intervention.

\section{Methods}

Trial Design and Intervention Components

The study was a two-arm (intervention and control group) randomized controlled trial (RCT) The intervention design was based on a pilot project that produced encouraging results with respect to adherence and behaviour change (Jones et al., 2010). The intervention group received a six-month physical activity intervention. The physical activity component was based on the 2007 American College of Sports Medicine (ACSM) (Haskell et al., 2007) and American Heart Association (AHA) physical activity guidelines (Pollock et al., 2000). Dietary information was also provided and outcome data collected but due to the complexity of the analysis this will be presented separately.

The behaviour change theories and techniques used to assist in the development of the intervention included the Social Cognitive Theory (Glanz et al., 2008), Transtheoretical Model (Prochaska and Diclemente, 1983) and motivational interviewing (Rollnick and Miller, 1995). The 6-month home-based intervention provided information and advice on the recommended levels of physical activity (30 minutes of moderate physical activity on five or all days of the week) and appropriate muscle strength and flexibility exercises. The resources comprised a comprehensive booklet, muscle strength and flexibility exercise chart, physical activity diary and pedometer. There were four electronic (email) or hard copy (mail) newsletters containing health information and advice and 18 key short message service (SMS) on suitable health behaviours. The home based program was reinforced by five 30 minute monthly face to face workshops and skill development sessions delivered by 12 trained staff in the playgroup setting.

The resources/activities provided information on the health benefits of physical activity; encouraged skill development to support the integration of physical activity into daily living and goal setting; promoted discussion on the barriers and potential solutions to being active; supported increased self-efficacy and social support for physical activity; and provided skills to prevent relapse. Full details of the intervention are provided elsewhere (Monteiro et al., 2011). The control group did not receive the intervention, and the only contact with the project occurred when they completed the questionnaires. 


\section{Recruitment and Randomization}

Playgroup Western Australia (Playgroup WA Inc.) is the governing body for playgroups in the State. Playgroups provide an informal local setting for women and children to come together to socialise. Women attend the playgroup with their preschool child (usually 0-4years) on a set day every week. The playgroups are run by volunteer parents and are held in a variety of venues such as church halls, community centres and child health centres. Women submit applications to join the local playgroup. Each playgroup may have up to 10 sessions per week. The number of attendees at each session is usually restricted to about 10-12 families.

Playgroup WA staff contacted playgroups registered in the Perth metropolitan area and obtained consent for the project staff to visit the playgroups. The suburbs (neighborhoods) $(n=60)$ were matched for low and medium Socio-Economic Indexes for Area (SEIFA) values and then randomly assigned to the intervention $(n=30)$ or control ( $n=30)$ group (Australian Bureau of Statistics, 1998). (SEIFA values ranged from 866-1151)

To be eligible for participation in the study, participants were required to be: women aged 18 years and above; registered with Playgroup WA. Inc.; have at least one child aged 0-5 years; considered "healthy" to the extent that participation in a low-stress physical activity program would not place them at risk; and no special diet. The intervention group participants completed the Physical Activity Readiness Questionnaire (PARQ) (Thomas et al., 1992) and provided a medical certificate if deemed necessary before commencing the program. Of the 1140 participants who were recruited, 716 participants consented to the study and were randomized to either the intervention $(n=394)$ or control $(n=322)$ group (Figure 1).

Ethics approval was obtained from the Curtin University Human Research Ethics Committee (approval number HR 183/2008). Trial Registration: Australian and New Zealand Clinical Trials Registry ACTRN12609000735257. Further detailed information is published in the protocol article (Monteiro et al., 2011). 
Physical activity was assessed using the International Physical Activity Questionnaire-Short Version (IPAQ-SV) (Craig et al., 2003a). This instrument has been accepted as an appropriate physical activity measurement tool in many settings and measures physical activity in 'minutes/day' and 'days/week' (Craig et al., 2003b). Walking, moderate physical activity and vigorous physical activity were measured independently. Moderate intensity activities were defined as those that made one breathe somewhat harder than normal and increased the heart rate. Vigorous intensity activities were defined as activities that required hard physical effort and made one breathe much harder than normal ('huff and puff'). Muscle strength exercise questions were based on the American Heart Association (AHA) guidelines (Pollock et al., 2000) and measured in 'days' (Morrow et al., 2011).

\section{Statistical Analysis}

Descriptive statistics are reported as the mean $( \pm S D)$ for continuous data and percentages for categorical data. The effects of the intervention on continuous outcome measures were assessed using analysis of variance (ANOVA). All data was analysed including and excluding mothers who were pregnant, breastfeeding and postpartum (up to 12 months). The statistical analyses were performed using Statistical Package for Social Sciences (SPSS, Version 18) and $p$-values $<0.05$ were considered statistically significant.

The baseline data for the 716 participants, were used to determine the median (or 50th percentile) for vigorous, moderate and total physical activity, all expressed as minutes per week. These medians were subsequently used to categorise each of the physical activity variables into two groups, above and below the median. A McNemar test was used to assess the change in the status of the correlated data from above or below the median at baseline to above or below the median post-intervention for each of the physical activity variables comparing the two groups.

A change in the positive direction was due to a change in the number of participants who improved in physical activity as a result of a change from below the median at baseline to a change above the median post-intervention. A change in the negative direction indicating reduction in physical activity and was the result of a change from above the median at baseline to a change below the median post-intervention. Net change for each of the physical activity variables and for each of the groups was calculated as a change in the positive direction subtracting the change in the negative direction, expressed as percentage of subjects of the total sample. 


\section{Results}

A total of 521 participants (73\%) completed the study. At six-months, the overall attrition was $27.3 \%$ with $16 \%(n=50)$ being in the control group and $37 \%(n=145)$ in the intervention group.

(Insert Figure 1)

The mothers were generally above 25 years of age, with the distribution relatively similar between 25-35 and 35 years and over. The majority of women were classified as a healthy weight (60.8\%), 30.2\% were classified as overweight and $9 \%$ as obese. The majority of women (61.5\%) were university educated. (See Table 1).. Of those participants who did not complete the 6-month intervention, $29.7 \%$ were pregnant, postpartum or breastfeeding compared to $38 \%$ of mothers who completed the intervention $(p=0.040)$. Participants who withdrew from the study were slightly younger (about 9 months) $(p=0.044)$ and had a lower waist circumference $(2.8 \mathrm{~cm})$ $(p=0.025)$ compared to women who completed the study. Apart from these minor differences, those withdrawing before the completion of the study were comparable to those who completed the study. Mothers who withdrew were not significantly different in parity, participation in strength muscle group exercises, BMI and waist to hip ratio $(p>0.05)$.

(Insert Table 1)

The intervention had a significant effect on the weekly mean time for vigorous $(p=0.008)$, moderate $(p=0.023)$ and total physical activity $(p=0.001)$ but did not have an effect on muscle strength exercises ( $p>0.05)$ when compared to the control group.

(Insert Table 2)

The intervention group increased their weekly mean time for vigorous physical activity by 24 minutes, moderate physical activity by 23 minutes and total physical activity by 72 minutes. Excluding mothers who were pregnant, postpartum and breastfeeding, slightly larger differences were observed between groups. The intervention and control groups were not significant in the time spent on muscle strength exercises, both for all mothers ( $p>0.85)$ and excluding mothers who were pregnant, postpartum and breastfeeding $(p>0.64)$. 
The net change for each of the physical activity variables (moderate and vigorous) and for each of the groups is presented in Figure 2. It is calculated as a change in the positive direction subtracting the change in the negative direction, expressed as percentage of subjects of the total sample. Net change is calculated as the difference between the percentage of participants who improved, by moving to a higher category, and the percentage of subjects who were classified in a lower category of the outcome variable. The intervention group consistently showed a net positive change in the physical activity variables (moderate, vigorous, moderate + vigorous), whereas the control group consistently showed a net negative change.

(Insert Figure 2)

The percentage of participants who improved in each of the physical activity variables under the intervention were significantly greater than the participants who declined $(p<0.05)$. In the control group, however, the percentage of participants who improved in each of the physical activity variables were not significantly different from the participants who declined ( $p>0.05$ ). Similar results were observed when the data for all mothers were analysed and when data for mothers who were pregnant, postpartum and breastfeeding were excluded from the analysis.

\section{DISCUSSION}

\section{Sample Characteristics}

A review of the literature demonstrates that the REFRESH physical activity study may be the largest RCT (baseline sample size of 716 ) specifically targeting mothers with young children (aged between 0 to 5 years) (Craigie et al., 2011, Fahrenwald and Sharma, 2002, Fjeldsoe et al., 2010, Lombard et al., 2009a, Miller et al., 2002, O'Toole et al., 2003, Cramp and Brawley, 2006, Gaston and Prapavessis, 2009, Hausenblas et al., 2008, Huang et al., 2011, Jackson et al., 2011, Krummel et al., 2010, Polley et al., 2002, Thompson et al., 2008), except for the WIC studies which does not indicate if all women included had at least one child (Fahrenwald and Sharma, 2002, Krummel et al., 2010).

There has been limited community based intervention physical activity research programs aimed at reaching and retaining mothers of young children (Craigie et al., 2011, Fahrenwald and Sharma, 2002, Fjeldsoe et al., 2010, Lombard et al., 2009a, Miller et al., 2002, O'Toole et al., 2003). Such interventions may be particularly challenging due to the multiple role expectations placed on women during the childbearing years (Ransdell et al., 2004), the competing priorities and lifestyle 
challenges that often lead to fatigue, restrictions on time and decreased motivation (Bell and Lee, 2005, Borodulin et al., 2008, Symons Downs and Hausenblas, 2004, Brown et al., 2001). In addition, the financial costs of raising children can reduce available funds, thereby prohibiting mothers from joining physical activity programs that charge.

This program used the playgroup setting to reach the mothers' of young children to provide them with resources to support an increase in their levels of physical activity. The home-based support materials comprised an information booklet, exercise chart, pedometer, SMS messaging and newsletter, enabling the women to work around their family demands. However, the program was supplemented by five short face-toface sessions that reinforced the home-based program, providing an opportunity to clarify information and to interact in a supportive environment.

Considering the many competing demands of parenting, the number of mothers completing this six-month intervention was very encouraging, with an overall retention rate of $73 \%$ (intervention $63 \%$; control $84 \%$ ). The attrition rate in the control group (16\%) was lower when compared to studies with similar populations including Fjeldsoe et al. (25\%) (Fjeldsoe et al., 2010), Miller et al. (17\%) (Miller et al., 2002) and Craigie et al. (39\%)(Craigie et al., 2011).

It is also encouraging that the characteristics of those women who dropped out of the program were similar to completers (parity, participation in strength muscle group exercises, BMI and waist to hip ratio $(p>0.05)$ ), thereby increasing the relevance of the findings overall to this target group.

\section{Physical Activity}

The main objective of this intervention was to increase the physical activity levels of these mothers. Once again the results were encouraging with the intervention participants showing significant improvements in mean minutes per week of moderate $(p=0.023)$, vigorous $(p=0.008)$ and total physical activity $(p=0.001)$ when compared to the control group. These REFRESH study results are difficult to compare to previous research due to the differences in reporting techniques (example, minutes per day (Craigie et al., 2011), MET minutes per week (Lombard et al., 2009a), hard bouts minutes per week (Ostbye et al., 2009)). However, this study reported more encouraging results than those reported by the Active Mothers Postpartum (AMP) study (Ostbye et al., 2008, Ostbye et al., 2009), and HeLP study 
(Lombard et al., 2009a). The AMP and HeLP studies were predominantly face-toface structured physical activity class interventions, which perhaps could have been better tailored to the target groups needs. The REFRESH results were similar to the Moms on the Move $(M O M)$ study $(p<0.05)$ which was a predominantly telephone based intervention providing women the flexibility of being active at times convenient to them (Fahrenwald et al., 2004). The results in this study are also very positive, due to the program being primarily a home-based intervention supported by a face-toface component, making replication realisable (Noar et al., 2007).

In addition, when mothers who were pregnant, postpartum and breastfeeding were excluded from the analysis slightly larger differences in mean physical activity times were observed between the control and intervention groups. This is to be expected and highlights the need for consideration of the physiological demands of these conditions on women when designing interventions (Hartman et al., 2010, Dewey and Lovelady, 1993, Morrow et al., 2011). Specific programs may be required for these particular target groups.

\section{Muscle strength}

The number of days that participants completed muscle strength exercises did not increase during the 6-month intervention. This is not unexpected, as it was a lesser component of the intervention, with the focus being on aerobic activity. Interestingly, a review of the literature, indicated that this may be the first program that attempted to incorporate strength exercises into an intervention for this target group (Amorim et al., 2007, Birdsall et al., 2009, Dodd et al., 2010, Hartman et al., 2010, Keller et al., 2008, Kuhlmann et al., 2008, Ronnberg, 2010, Skouteris et al., 2010, Streuling et al., 2010, Thangaratinam and Jolly, 2010). The Australian national physical activity guidelines do not include muscle strength exercise guidelines (Egger et al., 1999) and for this reason, this type of activity may not be perceived as important for health benefits. This warrants further investigation and potentially more of a focus when designing interventions with the target group.

\section{Setting}

This study is one of a few interventions aimed at improving the physical activity of mothers with young children, which has been previously identified as a hard to reach group (Hartman et al., 2010). The intervention indicates that playgroups provide a valuable and viable setting to recruit, engage and retain mothers of young children in 
programs that support the adoption of health enhancing behaviours (Jones et al., 2010).

\section{Limitations}

This program was restricted to six-month duration, although this kind of timeframe should be adequate to reflect behaviour change (Keller et al., 2008, Kuhlmann et al., 2008). Similar to other interventions, self-selection bias can be an issue, as shown by the high number of university educated participants. However, this was minimised through the randomising of participants to the control and intervention groups. The collection of data on the age of children, length of time since birth and duration of breastfeeding would have provided greater insight into the target group but on consideration of subject burden these variables were collected. Finally, data were collected via self-complete questionnaires, which may lead to some over reporting of physical activity. The literature, however, suggests that self-report data has been found to be adequate for monitoring changes over time in such interventions, especially when a control group is also used (Eakin et al., 2009, Dhaliwal et al., 2010, Morey et al., 2009).

\section{Conclusions}

This relatively minimal intervention program was able to demonstrate modest but statistically significant improvements in physical activity behaviour (moderate, vigorous and total physical activity) in a hard to reach target group via the playgroup setting. These changes in behaviour, if maintained over a longer period are likely to reduce the impact of several chronic conditions such as Type 2 diabetes, cardiovascular disease and some cancers. In addition, the improved health behaviours of mothers is likely to also have a positive impact on their partners and children. It appears that this is one of the few effective physical activity interventions for mothers of young children reported to date (Amorim et al., 2007, Hartman et al., 2010, National Institute for Health and Clinical Excellence, 2011, National Institute for Health and Clinical Excellence, 2010) and possibly the first RCT to also assess changes in muscle strength exercise activities. Further investigation of viable physical activity interventions with this target group is recommended.

\section{Acknowledgements}

The authors are grateful to Dr Sharyn Burns (SB), Professor Alexandara McManus (AM) and Ms Carlie Jones (CJ) for their contribution to the study design during the initial phase of the project. We also acknowledge Dr Christina Pollard, Dr Deb Kerr 
and Mr Steve Pratt for their helpful advice. The Centre for Behavioural Research in Cancer Control (CBRCC) receives funding support from the Cancer Council Western Australia.

\section{Funding}

This study was funded by a three-year Australian National Health and Medical Research Council grant. The funder had no involvement in any aspect of the study or reporting of findings.

\section{Author Contributions}

SM coordinated the trial and drafted the manuscript. JJ, $\mathrm{PH}, \mathrm{AH}, \mathrm{SD}, \mathrm{SB}$ and $\mathrm{AA}$ designed the study and the contributed to the manuscript. SD and SM performed statistical analysis and interpreted the data. All of the authors contributed to the submitted version of the paper.

The authors declare that there are no conflicts of interest. 


\section{References}

Amorim, AR, Linne, YM, Lourenco, PMC, 2007. Diet, exercise, or both, for weight reduction in women after childbirth. Cochrane Database of Systematic Reviews.

Department of Families Housing Community Services and Indigenous Affairs Australia, 2008. Evaluation of the playgroup program: Final report. Playgroup Australia, Brunswick, Victoria.

Australian Bureau of Statistics, 1998. Census of population and housing: SocioEconomic Indexes For Areas 1996, Information paper. Australian Bureau of Statistics, Canberra.

Australian Bureau of Statistics, 2009. National health survey: Summary of results 2007-08 Cat no. 4364.0 Canberra.

Bastian, LA, Pathiraja, VC, Krause, K, Namenek Brouwer, RJ, Swamy, GK, Lovelady, CA, Ostbye, T, 2010. Multiparity is associated with high motivation to change diet among overweight and obese postpartum women. Womens Health Issues 20:133-138.

Bauman, A, Bull, F, Chey, T, Craig, CL, Ainsworth, BE, Sallis, JF, Bowles, HR, Hagstromer, M, Sjostrom, M, et al., 2009. The international prevalence study on physical activity: Results from 20 countries. Int J Behav Nut Phys Act 6:2132.

Bell, S, Lee, C, 2005. Emerging adulthood and patterns of physical activity among young australian women. Int J Beh Med 12:227-235.

Birdsall, K, Vyas, S, Khazaezadeh, N, Oteng-Ntim, E, 2009. Maternal obesity: A review of interventions. Int J Clin Prac 63:494.

Borodulin, K, Evenson, KR, Herring, AH, 2009. Physical activity patterns during pregnancy through postpartum. BMC Women's Health 9:32.

Borodulin, KM, Evenson, KR, Wen, F, Herring, AH, Benson, AM, 2008. Physical activity patterns during pregnancy. Med Sci Sports Exerc 40:1901-8.

Brown, P, Brown, W, Miller, Y, Hansen, V, 2001. Perceived constraints and social support for active leisure among mothers with young children. Leis Sci 23:131144.

Brown, WJ, Burton, NW, Rowan, PJ, 2007. Updating the evidence on physical activity and health in women. Am J Pre Med 33:404-411.

Callaway, LK, Prins, JB, Chang, AM, Mcintyre, HD, 2006. The prevalence and impact of overweight and obesity in an australian obstetric population. MJA 184:56-9.

Craig, C, Marshall, A, Sjostrom, M, Bauman, A, Booth, M, Ainsworth, B, Pratt, M, Ekelund, U, Yngve, A, et al., 2003. International physical activity questionnaire: 12-country reliability and validity. Med Sci Sports Exerc 35:1381-1395. 
Craigie, AM, Macleod, M, Barton, KL, Treweek, S, Anderson, AS, 2011. Supporting postpartum weight loss in women living in deprived communities: Design implications for a randomised control trial. Euro J Clin Nut 65:952-958.

Cramp, AG, Brawley, LR, 2006. Moms in motion: A group-mediated cognitivebehavioral physical activity intervention. Int J Behav Nut Phys Act 6:23.

Davis, EM, Stange, KC, Horwitz, RI, 2010. Childbearing, stress and obesity disparities in women: A public health perspective. Matern Child Health $\mathrm{J} 16$ : 109-118.

Dewey, KG, Lovelady, C, 1993. Exercise and breast-feeding: A different experience. Pediatr 91:514-5.

Dhaliwal, SS, Howat, P, Bejoy, T, Welborn, TA, 2010. Self-reported weight and height for evaluating obesity control programs. Am J Health Behav 34:489-99.

Dodd, JM, Grivell, RM, Crowther, CA, Robinson, JS, 2010. Antenatal interventions for overweight or obese pregnant women: A systematic review of randomised trials. Br J Obstet Gynaecol 117:1316-1326.

Eakin, E, Reeves, M, Lawler, S, Graves, N, Oldenburg, B, Del Mar, C, Wilke, K, Winkler, E, Barnett, A, 2009. Telephone counseling for physical activity and diet in primary care patients. AM J Prev Med36:142-9.

Egger, G, Donovon, R, Swinburn, B, Giles-Corti, B, Bull, FC, 1999. Physical activity guidelines for australians: Scientific background report. A report by the university of western australia and the centre for health promotion and research sydney for the commonwealth department of health and aged care.

Evenson, KR, 2011. Towards an understanding of change in physical activity from pregnancy through postpartum. Psychol Sport Exerc 12:36-45.

Fahrenwald, NL, Atwood, JR, Walker, SN, Johnson, DR, Berg, K, 2004. A randomized pilot test of "moms on the move": A physical activity intervention for wic mothers. Ann Behav Med 27:82-90.

Fahrenwald, NL, Sharma, M, 2002. Development and expert evaluation of "moms on the move," a physical activity intervention for wic mothers. Women, infants, and children. Public Health Nurs 19:423-39.

Fjeldsoe, BS, Miller, YD, Marshall, AL, 2010. Mobilemums: A randomized controlled trial of an sms-based physical activity intervention. Ann Behav Med39:101-11.

Gaston, A, Prapavessis, H, 2009. Maternal-fetal disease information as a source of exercise motivation during pregnancy. Health Psych 28:726-33.

Glanz, K, Rimer, BK, Lewis, FM, 2008. Health behaviour and health education: Theory, research and practice. Jossey-Bass, San Francisco. 
Gore, SA, Brown, DM, West, DS, 2003. The role of postpartum weight retention in obesity among women: A review of the evidence. Ann Behav Med 26:149-59.

Hartman, MA, Hosper, K, Stronks, K, 2010. Targeting physical activity and nutrition interventions towards mothers with young children: A review on components that contribute to attendance and effectiveness. Public Health Nutr 14:1364-81.

Haskell, W, Lee, I, Pate, R, Powell, K, Blair, S, Franklin, B, Macera, C, Heath, G, Thompson, $\mathrm{P}$, et al., 2007. Physical activity and public health: Updated recommendations for adults from the american college of sports medicine and american heart association. Circulation 116:1-13.

Hausenblas, HA, Brewer, BW, Van Raalte, JL, Cook, B, Downs, DS, Weis, CA, Nigg, C, Cruz, A, 2008. Development and evaluation of a multimedia cd-rom for exercise during pregnancy and postpartum. Patient Educ Couns 70:215-219.

Huang, TT, Yeh, CY, Tsai, YC, 2011. A diet and physical activity intervention for preventing weight retention among taiwanese childbearing women: $\mathrm{A}$ randomised controlled trial. Midwifery 27:257-264.

Jackson, RA, Stotland, NE, Caughey, AB, Gerbert, B, 2011. Improving diet and exercise in pregnancy with video doctor counseling: A randomized trial. Patient Educ Couns 83:203-209.

Jones, C, Burns, S, Howat, P, Jancey, J, Mcmanus, A, Carter, O, 2010. Playgroup as a setting for nutrition and physical activity interventions for mothes with young children: Exploratory qualitative findings. Health Promot J Austr 21:92-98.

Keitt, SK, Resnick, EM, Simon, VR, Iskikian, SO, Marts, SA, 2008. Behavior and obesity in women across the life span: A report by the society for women's health research. J Investig Med 56:830-42.

Keller, C, Records, K, Ainsworth, B, Permana, P, Coonrod, DV, 2008. Interventions for weight management in postpartum women. J Obstet Gynecol Neonatal Nurs 37:71-9.

Krummel, DA, Semmens, E, Macbride, AM, Fisher, B, 2010. Lessons learned from the mothers' overweight management study in 4 west virginia wic offices. J Nutr Educ Behav 42:S52-S58.

Kuhlmann, AKS, Dietz, PM, Galavotti, C, England, LJ, 2008. Weight-management interventions for pregnant or postpartum women. Am J Prev Med 34:523-528.

Lee, DC, Sui, X, Blair, SN, 2009. Does physical activity ameliorate the health hazards of obesity? Br J Sports Med 43:49-51.

Lee, IM, Shiroma, EJ, Lobelo, F, Puska, P, Blair, SN, Katzmarzyk, PT, 2012. Effect of physical inactivity on major non-communicable diseases worldwide: An analysis of burden of disease and life expectancy. Lancet 380:219-29. 
Linne, Y, Dye, L, Barkeling, B, Rossner, S, 2004. Long-term weight development in women: A 15-year follow-up of the effects of pregnancy. Obes Rev 12:1166-78.

Liu, J, Blair, SN, Teng, Y, Ness, AR, Lawlor, DA, Riddoch, C, 2011. Physical activity during pregnancy in a prospective cohort of british women: Results from the avon longitudinal study of parents and children. Eur J Epidemiol 26:237-47.

Liu, N, Mao, LM, Sun, XF, Liu, LG, Yao, P, Chen, BH, 2009. The effect of health and nutrition education intervention on women's postpartum beliefs and practices: $A$ randomized controlled trial. BMC Public Health 9.

Lombard, CB, Deeks, AA, Ball, K, Jolley, D, Teede, HJ, 2009. Weight, physical activity and dietary behavior change in young mothers: Short term results of the help-her cluster randomized controlled trial. Nutr J 8:17.

Lombard, CB, Deeks, AA, Teede, HJ, 2009. A systematic review of interventions aimed at the prevention of weight gain in adults. Public Health Nutr 12:22362246.

Miller, Y, Trost, S, Brown, W, 2002. Mediators of physical activity behavior change among women with young children. Am J Prev Med 23:98-103.

Monteiro, SMDR, Jancey, J, Howat, P, Burns, S, Jones, C, Dhaliwal, SS, Mcmanus, A, Hills, AP, Anderson, AS, 2011. The protocol of a randomized controlled trial for playgroup mothers: Reminder on food, relaxation, exercise, and support for health (REFRESH) program. BMC Public Health 11:648.

Morey, MC, Snyder, DC, Sloane, R, Cohen, HJ, Peterson, B, Hartman, TJ, Miller, P, Mitchell, DC, Demark-Wahnefried, W, 2009. Effects of home-based diet and exercise on functional outcomes among older, overweight long-term cancer survivors: Renew: A randomized controlled trial. JAMA 301:1883-1891.

Morrow, JR, Bain, TM, Frierson, GM, Trudelle-Jackson, E, Haskell, WL, 2011. Longterm tracking of physical activity behaviors in women: The win study. Med Sci Sport Exer 43:165-170.

National Institute for Health and Clinical Excellence, 2010. Dietary interventions and physical activity interventions for weight management before, during and after pregnancy. NICE: Public Health Guidance 27.

National Institute for Health and Clinical Excellence, 2011. Systematic review of weight management interventions after childbirth. The University of Sheffield, Public Health Collaborating Centre, London.

Noar, SM, Benac, CN, Harris, MS, 2007. Does tailoring matter? Meta-analytic review of tailored print health behavior change interventions. Psychol Bull 133:673-693.

O'toole, M, Sawicki, M, Artal, R, 2003. Structured diet and physical activity prevent postpartum weight retention. J Womens Health 12:991-8. 
Ostbye, T, Krause, KM, Brouwer, RJ, Lovelady, CA, Morey, MC, Bastian, LA, Peterson, BL, Swamy, GK, Chowdhary, J, et al., 2008. Active mothers postpartum (amp): Rationale, design, and baseline characteristics. J Womens Health 17:1567-75.

Ostbye, T, Krause, KM, Lovelady, CA, Morey, MC, Bastian, LA, Peterson, BL, Swamy, GK, Brouwer, RJN, Mcbride, CM, 2009. Active mothers postpartum: A randomized controlled weight-loss intervention trial. Am J Prev Med 37:173180.

Pivarnik, J, Chambliss, H, Clapp, J, Dugan, S, Hatch, M, Lovelady, C, Mottola, M, Williams, M, 2006. Impact of physical activity during pregnancy and postpartum on chronic disease risk. Med Sci Sport Exer 38:989.

Polley, BA, Wing, RR, Sims, CJ, 2002. Randomized controlled trial to prevent excessive weight gain in pregnant women. Int J Obs 26:1494-1502.

Pollock, ML, Franklin, BA, Balady, GJ, Chaitman, BL, Fleg, JL, Fletcher, B, Limacher, M, Pina, IL, Stein, RA, et al., 2000. Resistance exercise in individuals with and without cardiovascular disease : Benefits, rationale, safety, and prescription. An advisory from the committee on exercise, rehabilitation, and prevention, council on clinical cardiology, american heart association. Circulation 101:828-833.

Prochaska, JO, Diclemente, CC, 1983. Stages and processes of self-change of smoking - toward an integrative model of change. J Consult Clin Psychol 51:390-395.

Ramachenderan, J, Bradford, J, Mclean, M, 2008. Maternal obesity and pregnancy complications: A review. ANZ J Obs Gyn 48:228-235.

Ransdell, LB, Vener, JM, Sell, K, 2004. International perspectives: The influence of gender on lifetime physical activity participation. J R Soc Promot Health $124: 12-4$

Rollnick, S, Miller, WR, 1995. What is motivational interviewing? Behav Cogn Psychother 23:325-334.

Ronnberg, AK, 2010. Interventions during pregnancy to reduce excessive gestational weight gain: A systematic review assessing current clinical evidence using the grading of recommendations, assessment, development and evaluation (grade) system. Br J Obstet Gynaecol 117:1327.

Rooney, BL, Schauberger, CW, Mathiason, MA, 2005. Impact of perinatal weight change on long-term obesity and obesity-related illnesses. Obstet Gynecol 106:1349-1356.

Ruager-Martin, R, Hyde, M, Modi, N, 2010. Maternal obesity and infant outcomes. Early Hum Dev 86:715-722. 
Ryan, D, 2007. Obesity in women: A life cycle of medical risk. Int J Obes 31:S3-S7.

Siega-Riz, A, Viswanathan, M, Moos, M, Deierlein, A, Mumford, S, Knaack, J, Thieda, P, Lux, LJ, Lohr, KN, 2009. A systematic review of outcomes of maternal weight gain according to the institute of medicine recommendations:

Birthweight, fetal growth, and postpartum weight retention. Am J Obstet Gynecol 201:339.

Skouteris, H, Hartley-Clark, L, Mccabe, M, Milgrom, J, Kent, B, Herring, S, Gale, J, 2010. Preventing excessive gestational weight gain: A systematic review of interventions. Obes Rev 11:757-68.

Streuling, I, Beyerlein, A, Von Kries, R, 2010. Can gestational weight gain be modified by increasing physical activity and diet counseling? A meta-analysis of interventional trials. Am J Clin Nutr 92:678-687.

Symons Downs, D, Hausenblas, $H, 2004$. Women's exercise beliefs and behaviors during their pregnancy and postpartum. J Midwifery Womens Health 49:138.

Thangaratinam, S, Jolly, K, 2010. Obesity in pregnancy: A review of reviews on the effectiveness of interventions. Br J Obstet Gynaecol 117:1309.

Thomas, S, Reading, J, Shephard, RJ, 1992. Revision of the physical activity readiness questionnaire (par-q). Can J Sport Sci 17:338-45.

Thompson, JL, Allen, P, Helitzer, DL, Qualls, C, Whyte, AN, Wolfe, VK, Herman, CJ, 2008. Reducing diabetes risk in american indian women. Am J Prev Med:192201.

Tobias, D, Zhang, C, Van Dam, R, Bowers, K, Hu, F, 2011. Physical activity before and during pregnancy and risk of gestational diabetes mellitus: A meta-analysis. Diabetes Care 34:223.

U.S. Department of Health and Human Servies (Usdhhs), 1996. Physical activity and health: A report of the surgeon general, USDHHS. Center for Disease Control and Prevention (CDC), Atlanta.

Walker, LO, Wilging, S, 2000. Rediscovering the "m" in "mch": Maternal health promotion after childbirth. J Obstet Gynecol Neonatal Nurs 29:229-36.

World Health Organisation, 2008. The global burden of disease (2004 update), in: World Health Organisation (Ed.), Geneva.

World Health Organisation, 2010. Global recommendations on physical activity for health. World Health Organisation, Geneva. 
Table 1: Demographics of study group at baseline. Continuous variables are presented as Mean \pm Standard Deviation (Count) and categorical variables are presented as Count (Percentage).

\begin{tabular}{|c|c|c|c|c|}
\hline & \multicolumn{2}{|c|}{ Completed } & \multicolumn{2}{|c|}{ Withdrew } \\
\hline & Intervention & Control & Intervention & Control \\
\hline $\mathbf{N}$ & 249 & 272 & 145 & 50 \\
\hline Age (years) & $35.9 \pm 4.3(249)$ & $35.6 \pm 4.3(272)$ & $34.6 \pm 5(139)$ & $36 \pm 4.3(49)$ \\
\hline \multicolumn{5}{|l|}{$\begin{array}{l}\text { Pregnant, Breastfeeding } \\
\text { or Postpartum }\end{array}$} \\
\hline No & $146(58.6 \%)$ & $177(65.1 \%)$ & $97(66.9 \%)$ & $38(76 \%)$ \\
\hline Yes & $103(41.4 \%)$ & $95(34.9 \%)$ & $45(31 \%)$ & $12(24 \%)$ \\
\hline \multicolumn{5}{|l|}{ Parity } \\
\hline 1 & $82(32.9 \%)$ & $94(34.6 \%)$ & $60(42.9 \%)$ & $15(30 \%)$ \\
\hline 2 or more & $167(67.1 \%)$ & $178(65.4 \%)$ & $80(57.1 \%)$ & $35(70 \%)$ \\
\hline Body Mass Index (kg/m2) & $24.9 \pm 4.6(134)$ & $24.2 \pm 4.6(173)$ & $24.4 \pm 6.5(92)$ & $23.1 \pm 3.2(37)$ \\
\hline Waist circumference (cm) & $86 \pm 12(134)$ & $84.8 \pm 10.7(173)$ & $82.7 \pm 13.6(87)$ & $82 \pm 10.4(34)$ \\
\hline Waist-hip ratio (cm) & $0.9 \pm 0.3(134)$ & $0.9 \pm 0.1(173)$ & $0.8 \pm 0.1(87)$ & $0.9 \pm 0.1(34)$ \\
\hline \multicolumn{5}{|l|}{$\begin{array}{l}\text { Strength Exercises Major } \\
\text { Muscle Group }\end{array}$} \\
\hline No & $197(83.8 \%)$ & $204(78.5 \%)$ & $111(84.1 \%)$ & $37(78.7 \%)$ \\
\hline Yes & $38(16.2 \%)$ & $56(21.5 \%)$ & $21(15.9 \%)$ & $10(21.3 \%)$ \\
\hline
\end{tabular}


Table 2: Comparison of physical activity variables (mean minutes per week) between intervention and control groups. Pre, Post and Difference are expressed as Mean \pm Standard Error (Count)

\begin{tabular}{|c|c|c|c|c|c|}
\hline & & Intervention & Control & P-value & $\begin{array}{l}\text { Group difference } \\
\text { Mean }(95 \% \text { CI) }\end{array}$ \\
\hline \multicolumn{6}{|l|}{ All mothers } \\
\hline \multirow[t]{3}{*}{ Vigorous } & Pre & $59.5 \pm 5.5(237)$ & $81.6 \pm 7.1(265)$ & & \\
\hline & Post & $76.2 \pm 6.5(237)$ & $74.7 \pm 6.7(265)$ & & \\
\hline & Difference (Post-Pre) & $16.8 \pm 6.3$ & $-7.3 \pm 6.5$ & .008 & $24.1(6.2,42.0)$ \\
\hline \multirow[t]{3}{*}{ Moderate } & Pre & $76.5 \pm 5.1(237)$ & $94.7 \pm 6.8(263)$ & & \\
\hline & Post & $100.8 \pm 6.4(237)$ & $94.2 \pm 7.2(263)$ & & \\
\hline & Difference (Post-Pre) & $25.2 \pm 6.9$ & $1.9 \pm 7.5$ & 0.023 & $23.3(3.3,43.4)$ \\
\hline \multirow{3}{*}{$\begin{array}{l}\text { Vigorous, } \\
\text { Moderate, } \\
\text { Walking }\end{array}$} & $\overline{\text { Pre }}$ & \multicolumn{4}{|c|}{$195.1 \pm 13.5(238) 257.5 \pm 17.6(265)$} \\
\hline & Post & \multicolumn{4}{|c|}{$252.8 \pm 16.4(238) 243.2 \pm 17.6(265)$} \\
\hline & Difference (Post-Pre) & $58.5 \pm 15.2$ & $-13.7 \pm 14.8$ & .001 & $72.2(30.4,114)$ \\
\hline \multirow{3}{*}{$\begin{array}{l}\text { Muscle } \\
\text { strength } \\
\text { exercises }\end{array}$} & $\overline{\text { Pre }}$ & $22 \pm 2.8(222)$ & $24.6 \pm 2.6(250)$ & & \\
\hline & Post & $19.3 \pm 2.3(222)$ & $20.4 \pm 2.4(250)$ & & \\
\hline & Difference (Post-Pre) & $-4.0 \pm 2.7$ & $-4.7 \pm 2.4$ & .852 & $0.7(-6.3,7.6)$ \\
\hline \multicolumn{6}{|c|}{ Excluding mothers who are pregnant, breastfeeding or postpartum } \\
\hline \multirow[t]{3}{*}{ Vigorous } & Pre & $65.9 \pm 7.3(135)$ & $80.9 \pm 7.8(172)$ & & \\
\hline & Post & $88.1 \pm 8.9(135)$ & $75.5 \pm 8.1(172)$ & & \\
\hline & Difference (Post-Pre) & $21.8 \pm 7.7$ & $-5.4 \pm 7.7$ & .014 & $27.3(5.5,49.0)$ \\
\hline \multirow[t]{3}{*}{ Moderate } & Pre & $82.1 \pm 7.2(134)$ & $104 \pm 8.2(170)$ & & \\
\hline & Post & $99 \pm 8.3(134)$ & $92.5 \pm 8.5(170)$ & & \\
\hline & Difference (Post-Pre) & $18.1 \pm 9.3$ & $-8.2 \pm 8.3$ & .036 & $26.3(1.7,50.8)$ \\
\hline \multirow{3}{*}{$\begin{array}{l}\text { Vigorous, } \\
\text { Moderate, } \\
\text { Walking }\end{array}$} & Pre & \multirow{2}{*}{\multicolumn{4}{|c|}{$\begin{array}{l}213.9 \pm 18.3(135) 265.3 \pm 20.1(172) \\
274.5 \pm 22.6(135) 242.9 \pm 21.7(172)\end{array}$}} \\
\hline & Post & & & & \\
\hline & Difference (Post-Pre) & $61.6 \pm 19.4$ & $-20.3 \pm 17.7$ & .002 & $82(30.2,133.8)$ \\
\hline \multirow{3}{*}{$\begin{array}{l}\text { Muscle } \\
\text { strength } \\
\text { exercises }\end{array}$} & $\overline{\text { Pre }}$ & $21.8 \pm 3.9(121)$ & $26 \pm 3.4(162)$ & & \\
\hline & Post & $22.5 \pm 3.3(121)$ & $23.4 \pm 3.2(162)$ & & \\
\hline & Difference (Post-Pre) & $-1.5 \pm 3.9$ & $-3.7 \pm 2.9$ & .641 & $2.2(-7.2,11.7)$ \\
\hline
\end{tabular}

Physical activity variables: vigorous intensity, moderate (mod) intensity, walking and muscle strength exercises were calculated in minutes per week 
Figure 1 - Flow chart of intervention and control participants

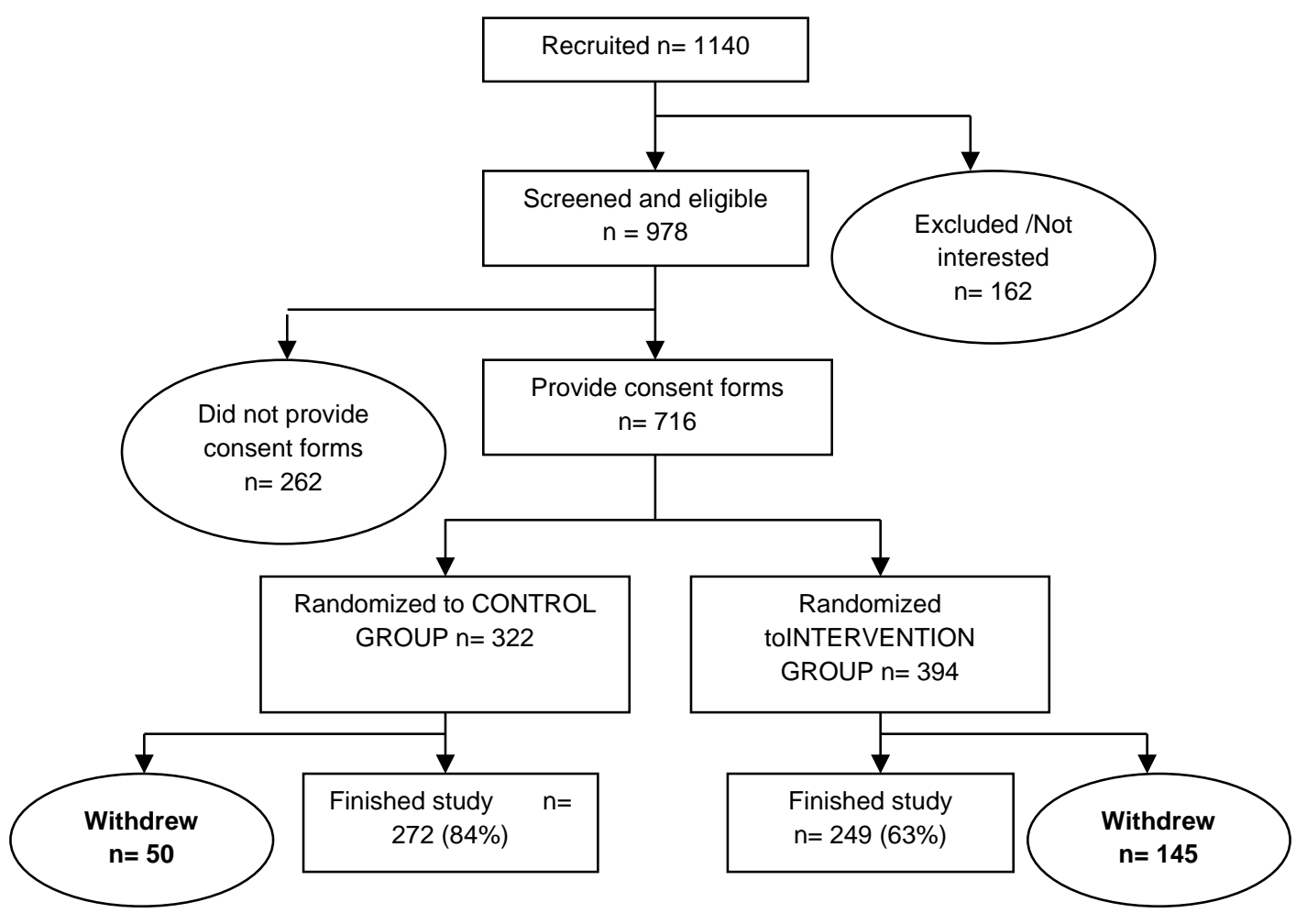


Figure 2: Net change expressed as difference between percentage of participants who improve and participants who did not improve for each type of physical activity, in both intervention (light grey colour) and control (black colour) groups.
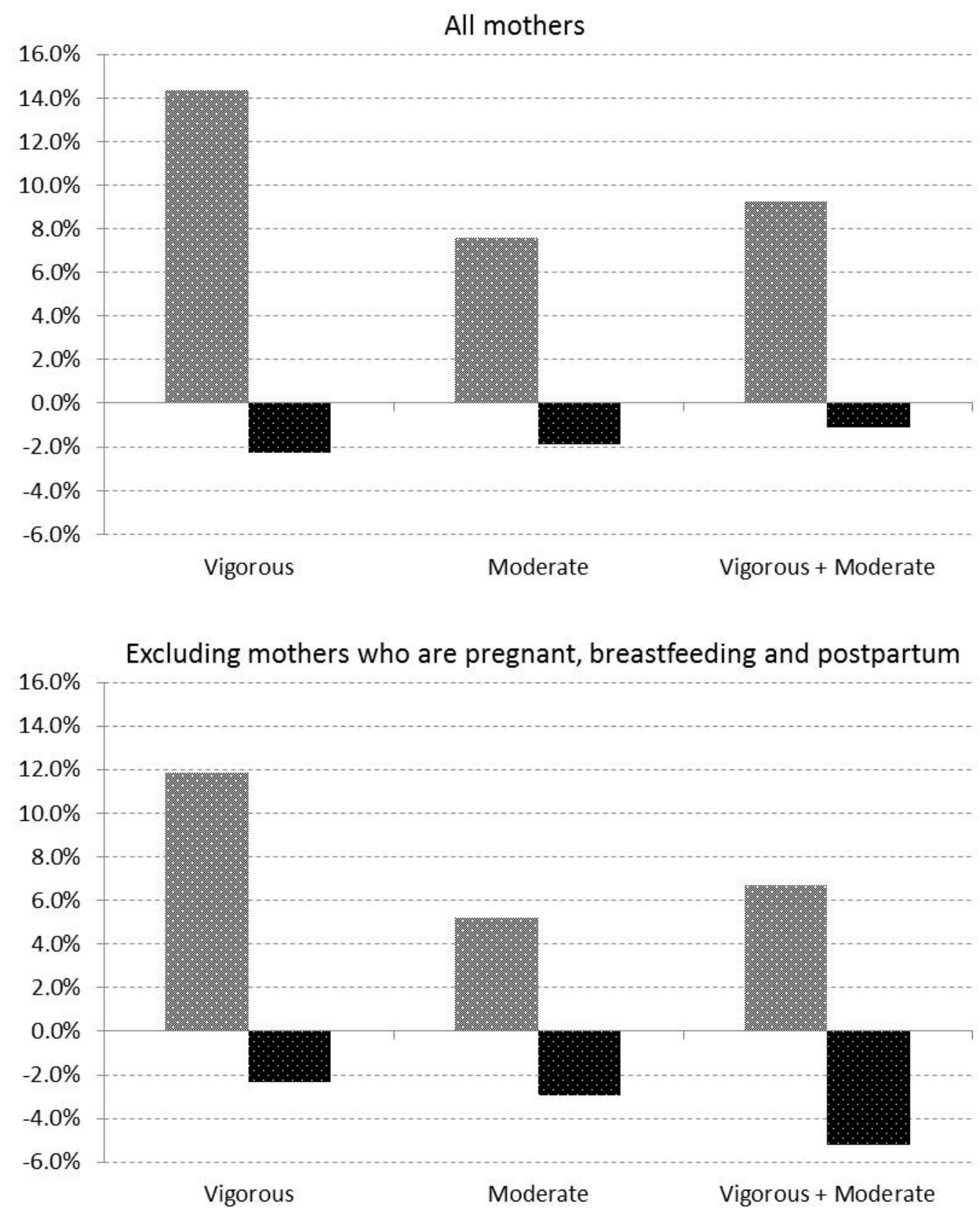